\title{
Ballistic Efficiency of an Individual Epoxy Composite Reinforced with Sisal Fibers in Multilayered Armor
}

\author{
Lazaro Araujo Rohen ${ }^{a}$, Frederico Muylaert Margem ${ }^{a}$, Sergio Neves Monteiro ${ }^{b * *}$ \\ Carlos Maurício Fontes Vieira ${ }^{a}$, Bruna Madeira de Araujo ${ }^{b}$,Eduardo Sousa Lima ${ }^{b}$
}

\author{
${ }^{a}$ Laboratório de Materiais Avançados - LAMAV, Universidade Estadual do Norte Fluminense - UENF, \\ Av. Alberto Lamego, 2000, Campos dos Goytacazes, CEP 28013-602, Rio de Janeiro, RJ, Brazil \\ ${ }^{b}$ Departamento de Ciências dos Materiais, Instituto Militar de Engenharia - IME, Praça General \\ Tibúrcio, 80, Praia Vermelha, Urca, CEP 22290-270, Rio de Janeiro, RJ, Brazil
}

Received: November 6, 2014; Revised: July 28, 2015

\begin{abstract}
Sisal fibers are among the natural lignocellulosic ones with great impact resistance for potential use in polymer composites. This work evaluates the ballistic efficiency of the distinct individual components of a multilayered armor. These include the front ceramic, the back metallic sheet and the intermediate layer as either the conventional aramid fabric or a novel sisal fiber reinforced epoxy composite. Sisal fibers incorporated in epoxy resin plates with volume fraction of $30 \%$ were ballistic tested using the 7.62 caliber ammunition. The fibers were embedded under pressure in the epoxy resin matrix and cured at room temperature for 24 hours. The tested specimens were examined by scanning electron microscopy.
\end{abstract}

Keywords: sisal fiber, ballistic impact, epoxy composite

\section{Introduction}

A portable armor vest for body protection should be a low cost and lightweight wearable garment system with ballistic impact resistance ${ }^{1}$. The NIJ standards ${ }^{2}$ specify that body armor should stop a projectile and prevent its penetration into a clay witness backing the armor to a depth not exceeding 1.73 inches $(44 \mathrm{~mm})$. Beyond this depth the penetration can potentially cause serious blunt trauma to the human armor wearer ${ }^{3}$. Armor vests against relatively heavy ammunition, such as the $7.62 \times 51 \mathrm{~mm}$ NATO caliber bullet, require multilayered armor systems (MAS) combining relatively lighter materials ${ }^{4-6}$ The MAS aims not only at absorbing the impact energy of the projectile but also to impede the penetration of fragments from both the projectile and, mainly, the front ceramic ${ }^{7,8}$.

For these purposes, MAS are usually composed of a harder front ceramic plate with the ability to deform, shatter and erode/fracture the projectile ${ }^{9-12}$. Owing to this ceramic front layer, a large amount of the impact projectile energy is dissipated through the ceramic fragmentation involving nucleation, growth and coalescence of micro cracks ${ }^{13}$. As the projectile impacts the front ceramic plate, a compressive wave propagates and reaches the back of the plate ${ }^{14}$. There, the wave is partially reflected as a tensile pulse, which normally breaks the ceramic regardless of the material connecting the front layer ${ }^{6}$. A second MAS layer after the ceramic is usually chosen as a lighter composite material, which reduces even further the impact wave by absorbing part of the fragments (projectile or ceramic) kinetic energy. For this second layer, aramid fabrics, such as Kevlar ${ }^{\mathrm{TM}}$ and $\operatorname{Twaron}^{\mathrm{TM}}[1,8]$, as well

*e-mail: snevesmonteiro@gmail.com as ultra high molecular polyethylene UHPE fibers, such as Spectra $^{\mathrm{TM}}$ and Dyneema ${ }^{\mathrm{TM}}[15,16]$, are currently the choices for lightweight body armor composites. These composites absorb part of the remaining projectile or ceramic fragments energy by means of fabric debonding, yarn stretching, fabric plies bending and eventual rupture mechanisms ${ }^{17}$. Without the front ceramic tile, which is the main protection in a $\mathrm{MAS}^{11,12}$, a monolithic large thickness of aramid or UHPE fabric would be required for protection against a relatively high energy projectile ${ }^{8}$. This would limit the comfort and mobility of a portable armor vest. A complete MAS system may also include a third ductile metallic layer acting as a final barrier. This restricts even further the penetration of the projectile or its fragments beyond the maximum standard depth of $44 \mathrm{~mm}$, which causes serious injure to a human body.

As the lighter component of a body armor vest, the second intermediate composite layer is not only intended to provide comfort and mobility to the wearer but also to improve the absorption efficiency of the projectile impact. Indeed, upon projectile impact a compressive wave travels and reflects through the several layers of a MAS ${ }^{18}$. If a lower impedance composite stands behind the ceramic interface, a tensile wave is reflected and the proceeding compressive wave will be comparatively lower in transmitted energy. As the shock impedance is directly related to the material's density, a greater ballistic impact energy reduction should be provided by a comparatively lighter composite backing the ceramic $_{\text {plate }}{ }^{18}$. The substitution of an even lower density composite for the aramid fabric should be a possible alternative to improve the impact absorption. In principle, a candidate could be a lighter polymer composite reinforced with low 
density lignocellulosic fibers obtained from plants. These lignocellulosic fibers, in addition to a lower density than aramid fiber, are much less expensive, abundant, renewable, degradable, recyclable and regarded as environmentally friendly. Moreover, they are not as energy intensive as synthetic fibers, such as glass, carbon and aramid fibers, during processing ${ }^{19}$. In past decades, thousands of works on polymer composites reinforced with lignocellulosic fibers have been published in association with recent review papers $^{20-23}$. Moreover, these composites were applied in several engineering sectors, particularly, the automotive industry ${ }^{24-26}$. In particular, the sisal fiber extracted from the leaves of the Agave sisalana plant, native of the Amazon region, was reported to have a density of $1.26-1.50 \mathrm{~g} / \mathrm{cm}^{3}$, tensile strength of $287-913 \mathrm{MPa}$ and Young's modulus of $9-28 \mathrm{GPa}^{[19]}$. Epoxy composites reinforced with $30 \%$ sisal fibers reached Charpy impact energy over $330 \mathrm{~J} / \mathrm{m}^{[27]}$.

To the knowledge of the authors of the present work, Wambua et al. ${ }^{28}$ were probably the first group to conduct a systematic investigation on the ballistic properties of lignocellulosic fibers reinforcing polymer composites. Although presenting relevant information on the ballistic impact velocity and energy related to flax, hemp and jute fibers incorporated into polypropylene matrix composites, it was not the scope of Wambua et al. ${ }^{28}$ work to assess the performance of their system as armor for human body protection.

In the present work, the ballistic performance of multilayered armors composed of ceramic, fiber composites and aluminum layers was investigated in terms of penetration into clay witness simulating a human body. Ballistic tests were conducted in MAS's with a front $\mathrm{Al}_{2} \mathrm{O}_{3}$ tile. As the following intermediate layer, lighter sisal fiber reinforced epoxy composite plates were compared (same thickness), to plain epoxy plates and aramid fiber plies. The contribution of each material was also assessed by individual ballistic tests. The fracture aspects of these different intermediated layer materials, as single targets, were analyzed by scanning electron microscopy.

\section{Material and Methods}

The following materials, either composing a MAS or alone, were used in the present work. The front ceramic layer was a $15 \mathrm{~mm}$ thick hexagonal plate with $31 \mathrm{~mm}$ of side dimension and made of $4 \mathrm{wt} \% \mathrm{Nb}_{2} \mathrm{O}_{5}$ doped $\mathrm{Al}_{2} \mathrm{O}_{3}$ (ceramic). The conveniently smaller side dimension is chosen enough to accommodate the cone of pressure responsible for ceramic fragmentation. These plates were manufactured by sintering commercial purity $\mathrm{Al}_{2} \mathrm{O}_{3}$ powder supplied by Treibacher Schleifmittel mixed with $99 \%$ pro-analysis $\mathrm{Nb}_{2} \mathrm{O}_{5}$ powder supplied by the Companhia Brasileira de Mineração e Metalurgia. Sintering was carried out at $1,400{ }^{\circ} \mathrm{C}$ for 3 hour under air.

The intermediate layer, with $10 \mathrm{~mm}$ in thickness and square sides with $150 \mathrm{~mm}$, was either: (i) 16 plies of aramid fabric (aramid), or (ii) $30 \mathrm{vol} \%$ of continuous and aligned sisal fibers reinforced epoxy matrix composite (sisal composite) plates, or (iii) plain epoxy plate. Previous works on sisal fiber/epoxy composites have shown that the highest impact resistance ${ }^{27}$ and strength ${ }^{29}$ were obtained for $30 \mathrm{vol} \%$ fraction of sisal fibers. The aramid fabric plies were produced by Dupont and supplied by the Brazilian firm LFJ Blindagem Com. Serv. S.A. The sisal fiber was supplied by the Sisalsul firm in the form of a bundle. Fibers were separated from the bundle, dried at $60{ }^{\circ} \mathrm{C}$ in a laboratory oven for 2 hours, and aligned with the correct amount inside a steel mold. An initially fluid diglycidyl ether of the bisphenol-A (DGEBA) epoxy resin, mixed with a phr 13 stoichiometric fraction of trietylene tetramine (TETA) as hardener, was poured onto the mold. A pressure of $5 \mathrm{MPa}$ was applied and each composite plate cured at room temperature for 24 hours. Figure 1 illustrates: (a) a plate of ceramic; (b) a plate of sisal composite and (c) aramid fabric. In a similar procedure, plain DGEBA/TETA epoxy plates were also manufactured. The back end-layer was a $150 \times 150 \mathrm{~mm} 5052-\mathrm{H} 34$ aluminum alloy (Al) sheet with $5 \mathrm{~mm}$ in thickness. These layers were bonded in the MAS with commercial Sikaflex ${ }^{\mathrm{TM}}$ adhesive from Sika Co. A very thin layer, around $0.5 \mathrm{~mm}$, of Sikaflex ${ }^{\mathrm{TM}}$ (polyurethane) with similar density $\left(1.30 \mathrm{~g} / \mathrm{cm}^{3}\right)$, causes a negligible effect on the impact wave reflection from either the aramid fabric $\left(1.44 \mathrm{~g} / \mathrm{cm}^{3}\right)$ or the sisal/epoxy composite $\left(1.12 \mathrm{~g} / \mathrm{cm}^{3}\right)$, both

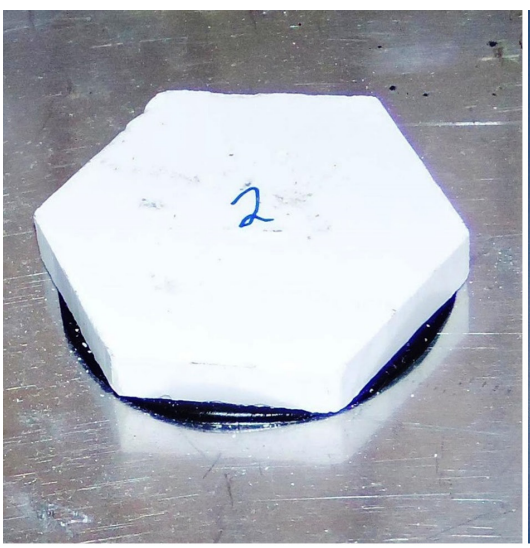

(a)

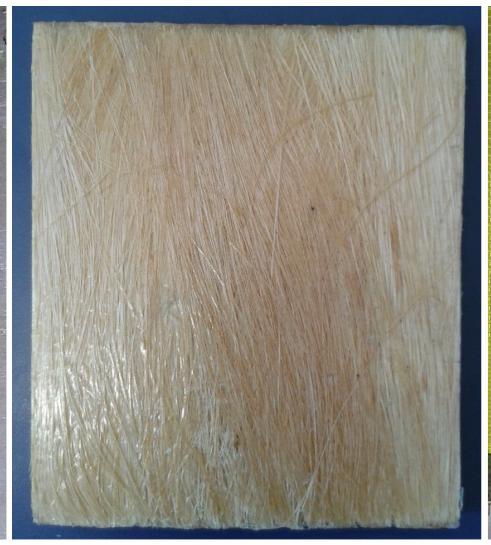

(b)

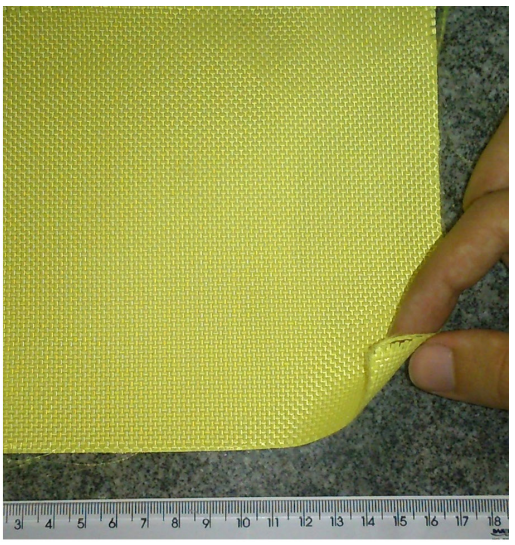

(c)

Figure 1. Components used in the investigated multilayered armor: (a) ceramic plate; (b) sisal composite plate and (c) aramid fabric plies. 
$10 \mathrm{~mm}$ thick. Figure 2 illustrates a complete MAS ready to be ballistic tested.

In direct contact with the Al sheet back end-layer, a block of clay witness simulated a human body protected by the MAS. Modeling clay, warmed at $40{ }^{\circ} \mathrm{C}$, according to the NIJ standard and compressed to avoid air bubbles, was commercially supplied by Corfix to be used as a clay witness. The trauma in the clay duplicates the plastic deformation imposed by the projectile impact on the Al sheet back layer. The corresponding indentation was measured, Figure 3, with a special Mitutoyo caliper with an accuracy of $0.01 \mathrm{~mm}$.

Ballistic tests were conducted at the Brazilian Army shooting range facility, CAEX, in the Marambaia peninsula, Rio de Janeiro. All tests, 10 for each type of MAS, were carried out according to the NIJ 0101.06 ${ }^{[2]}$ standard using $7.62 \times 51 \mathrm{~mm}$ NATO military ammunition with $9.7 \mathrm{~g}$ copper projectile, propelled from a gun barrel. A steel frame was used to position the target, which was held in place by clamps and spring clips. The gun, located $15 \mathrm{~m}$ from the target, was sighted on its center with a laser beam. The exact velocity of the projectile at two moments (leaving the gun and immediately before impacting the MAS) was measured by an optical barrier and a model SL-52 OP Weibel fixed-head Doppler radar system. Tests, in which the target was totally perforated, allowed the residual velocity of the outcoming projectile or fragments to be was also measured. The Weibull statistical analysis was applied to the experimental results. Fractured samples of each MAS component after the ballistic test were analyzed by scanning electron microscopy (SEM) in either a model JSM 6460 LV Jeol or a model QUANTA FEG250 Fei microscope, operating with secondary electrons at $20 \mathrm{kV}$.

\section{Results and Discussion}

\subsection{Multilayered armor ballistic performance}

In all MAS ballistic tests, the projectile was always stopped and its kinetic energy was dissipated inside the multilayered armor leaving an indentation in the clay witness, as shown in Figure 3. To evaluate the individual ballistic behavior of each distinct intermediate layer, tests were separately performed in the ceramic tile, aramid fabric plies, sisal composite plate and plain epoxy plate. In these tests, contrary to the MAS tests, the target was always perforated. Therefore, in addition to the impact velocity, the projectile residual velocity after perforation could also be measured.

Table 1 presents the average depth of indentation measured in the clay witness for the different MAS target investigated. In this table, some points are worth mentioning. The three materials tested as the intermediate layer that follows after the front ceramic layer, showed corresponding indentation depth below the $\mathrm{NIJ}^{2}$ limit of $44 \mathrm{~mm}$ for serious blunt

Table 1. Average depth of indentation in the clay witness backing different multilayered armors.

\begin{tabular}{lc}
\hline \multicolumn{1}{c}{ Intermediate Material Layer } & Indentation (mm) \\
\hline Aramid fiber plies & $22.67 \pm 2.79$ \\
Epoxy composite reinforced with & $18.18 \pm 2.06$ \\
$30 \%$ sisal fiber & \\
Plain epoxy plate & $19.84 \pm 1.09$ \\
\hline
\end{tabular}

trauma. The aramid fabric with an average indentation of $22.67 \pm 2.79 \mathrm{~mm}$ displays the deepest indentation as compared to both the sisal composite, the shallowest indentation of $18.18 \mathrm{~mm}$, and the plain epoxy, with $19.84 \mathrm{~mm}$. The sisal composite indentation corresponds to a $20 \%$ more efficient ballistic performance, as compared with the aramid fabric. Furthermore, the sisal composite is lighter and less expensive than the aramid fabric. These are technical and economical advantages that might be considered when selecting the intermediate layer material for a MAS.

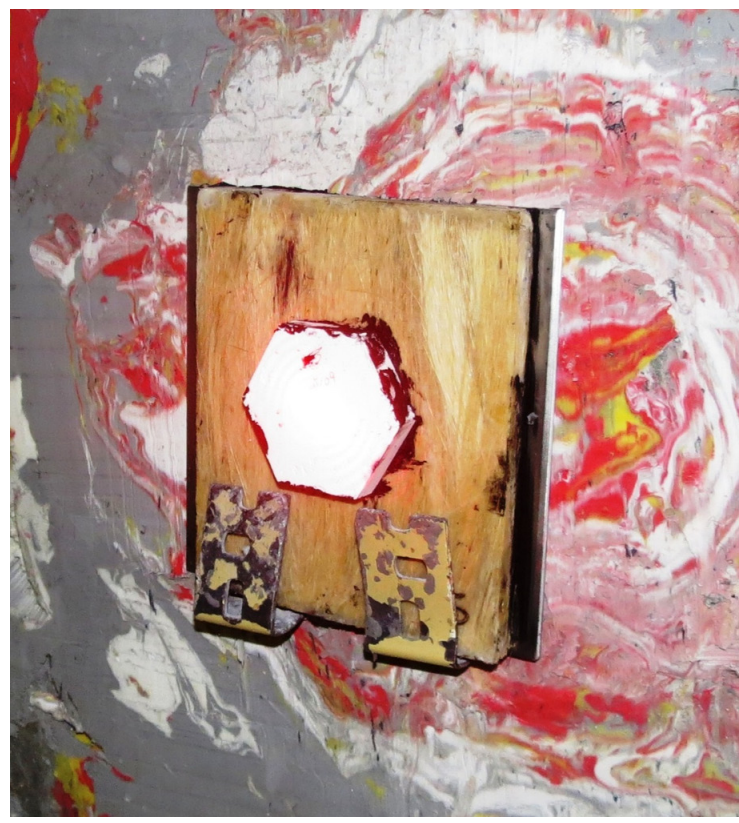

Figure 2. Complete multilayered armor clamped into the clay witness and ready to be ballistic tested.

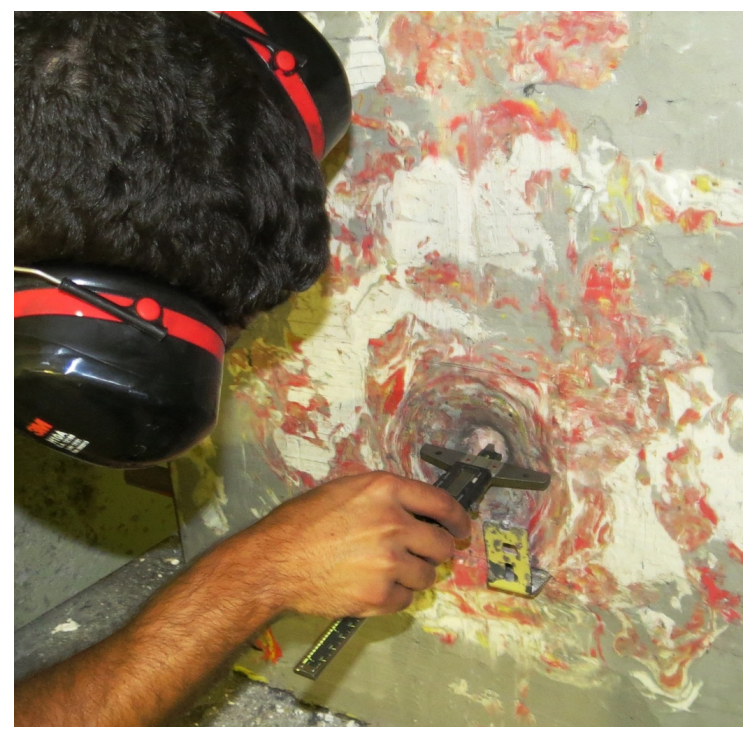

Figure 3. Measurement of the indentation in the clay witness caused by the projectile impact. 


\subsection{Ballistic penetration}

The ballistic performance of the MAS investigated was directly related to the energy absorption by the different layers. In separated tests, both the first $\mathrm{Al}_{2} \mathrm{O}_{3}$ ceramic layer as well as the second layer, either aramid or composite, and the $\mathrm{Al}$ sheet were perforated by the projectile. However, most of the energy was absorbed by the first and second MAS layers. After crossing the second layer, fragments (projectile or ceramic) were only able to cause a relatively small plastic deformation in the aluminum sheet back layer, which causes the indentation in the clay witness, Figure 3.

The perforation of the first ceramic layer, which is responsible for most of the energy dissipation ${ }^{5-12}$, was associated with shuttering of the brittle ceramic plate. In order to investigate its fracture, $\mathrm{Al}_{2} \mathrm{O}_{3}$ particles collected after the tests were observed by SEM after gold sputtering to provide an electrical conducting coating. Figure 4 shows the expected brittle fracture surface of a collected $\mathrm{Al}_{2} \mathrm{O}_{3}$ particle. As indicated by Medvedovski ${ }^{11,12}$, a 7.62 projectile causes different kinds of cracks to be formed during the impact. This complex pattern of propagating cracks associated with intercrystalline fracture is observed in Figure 4. Moreover, areas in Figure 4 were found by EDS to contain a significant amount of niobium, probably in a glassy phase.

Figure 5 shows the damage region of an aramid fabric plies after penetration by fragments (projectile/ceramic) resulting from the initial impact suffered by the front $\mathrm{Al}_{2} \mathrm{O}_{3}$ ceramic tile. The general features in this figure corroborates evidences of fabric yarn pullout, fiber stretching and fiber rupture reported by Lee et al. ${ }^{8}$. Additionally, Figure 5 reveals that bright and white particles of $\mathrm{Al}_{2} \mathrm{O}_{3}$ are attached to the fibers. This indicates that the aramid fabric contributes in the energy dissipation by capturing ceramic fragments. Small metallic particles from the projectile, although not shown in Figure 5, were also found entangled in the aramid fibers and so contributing to dissipate the energy.

Figure 6 presents the fracture region of a sisal composite after penetration by fragments (projectile/ceramic) resulting from the initial impact suffered by the front $\mathrm{Al}_{2} \mathrm{O}_{3}$ ceramic tile. In this figure, the main feature is the separation of

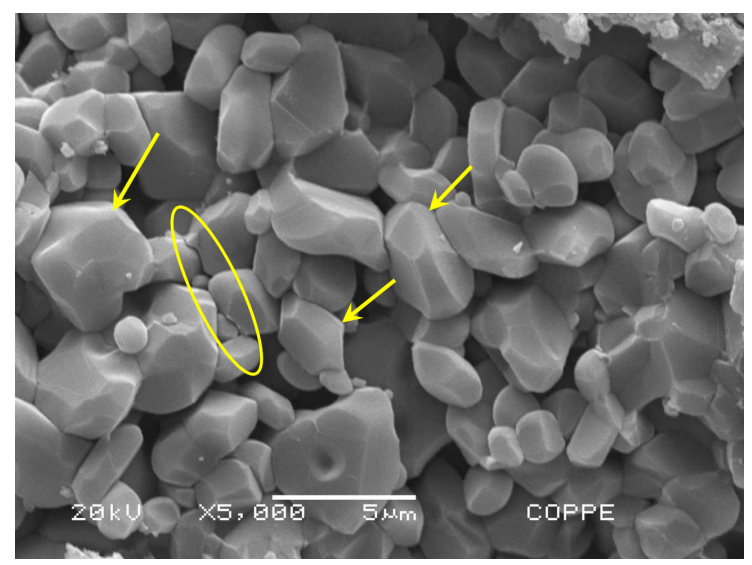

Figure 4. Intercrystalline fracture surface of an $\mathrm{Al}_{2} \mathrm{O}_{3}$ particle after the ballistic test, showing individual $\mathrm{Al}_{2} \mathrm{O}_{3}$ grains released in the fracture (arrows) and crack propagation (inside ellipse).

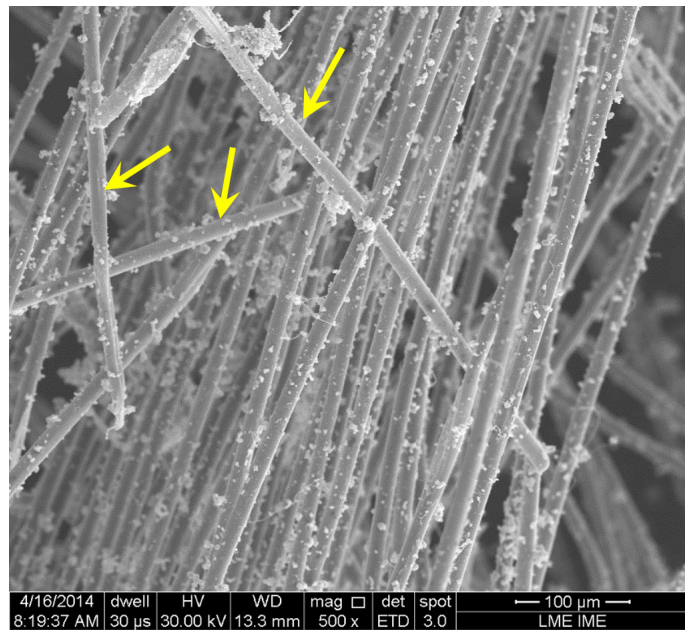

(a)

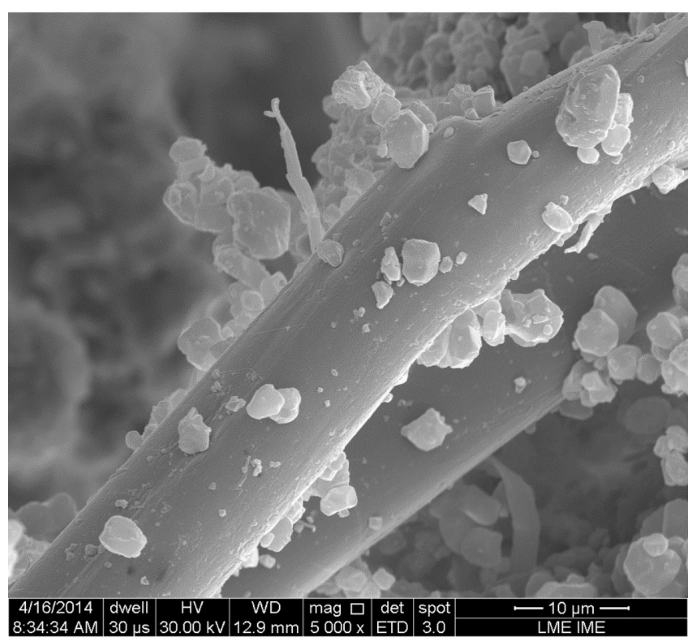

(b)

Figure 5. Damaged aramid fabric by fragments (projectile/ceramic) after the ballistic impact: (a) lower magnification, showing aramid fibers pulled out (arrows) from the yarn, and (b) higher magnification.

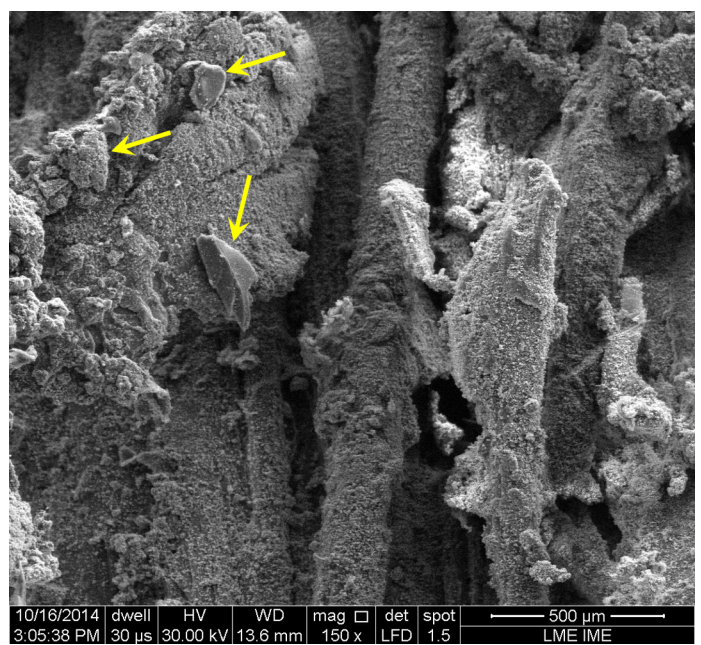

Figure 6. Fracture region of a sisal composite caused by fragments (projectile/ceramic) after the ballistic impact. Arrows indicating brittle epoxy pieces. 
sisal fibers in thinner fibrils, which is a characteristic of its mechanical rupture ${ }^{19}$. This contributes significantly to absorb the impact energy. Moreover, the fracture of the brittle epoxy matrix, pointed by arrow, is another source of energy dissipation. Similar to what was found in the damaged aramid fabric, Figure 5, the ballistic penetration of fragments also impregnated the sisal composite fracture by the bright and white ceramic particles in Figure 6.

\subsection{Ballistic performance of individual components}

The contribution of each MAS component was assessed by individual ballistic tests using the same ammunition, $7.62 \times 51 \mathrm{~mm}$ NATO, and methodology described in the previous section. The average impact velocity of $846 \mathrm{~m} / \mathrm{s}$ corresponds to a projectile kinetic energy of 3,471 J. Individual targets with the same thickness of the separate component layers indicated in Figure 1: $\mathrm{Al}_{2} \mathrm{O}_{3}$ ceramic tile, aramid fabric plies, sisal composite plate and plain epoxy plate, were tested in 10 samples of each. All targets were completed perforated after these individual tests. Not only the projectile impact velocity but also the residual velocity of the fragments passing through the target were measured by the Doppler radar system.

Figure 7 illustrates a typical radar spectrum obtained from an $\mathrm{Al}_{2} \mathrm{O}_{3}$ ceramic target. In this figure, one should note that an initial small horizontal segment indicates an impact velocity $\left(\mathrm{v}_{\mathrm{i}}\right)$ around $850 \mathrm{~m} / \mathrm{s}$. A sudden drop at about $0.015 \mathrm{~s}$ upon impact is associated with the attenuation of the velocity of outcoming fragments. For the ceramic, Figure 7, the corresponding radar spectrum displays more than one attenuation curve indicating the number of fragments (projectile/ceramic) that left the target. A second degree polynomial adjustment of these curves permitted to determine the residual velocity $\left(\mathrm{v}_{\mathrm{r}}\right)$ of the fragments by regression to the point of discontinuous drop, around $600 \mathrm{~m} / \mathrm{s}$ in Figure 7. The kinetic energy $\Delta \mathrm{E}_{\mathrm{d}}$, dissipated inside the target, could be estimated by the Equation 1:

$$
\Delta E_{d}=\frac{1}{2} m\left(v_{i}^{2}-v_{r}^{2}\right)
$$

Similar radar spectrum analyses were performed for aramid fabric, sisal composite and plain epoxy targets. In these cases, the residual velocities were found to be relatively closer to the corresponding impact velocities. Figure 8 exemplifies the experimental points obtained from the radar spectrum of a sisal composite and the adjusted continuous polynomial curve. In this figure, the regression to zero time gives the impact velocity, around $870 \mathrm{~m} / \mathrm{s}$, while the regression to the discontinuous drop provides the residual velocity, around $830 \mathrm{~m} / \mathrm{s}$. Similar graphs were obtained for the aramid fabric and the plain epoxy. On the contrary to the $\mathrm{Al}_{2} \mathrm{O}_{3}$ ceramic, just one attenuation curve was found for the aramid fabric and the plain epoxy, as in Figure 8.

Table 2 presents the impact and residual velocities as well as the internally dissipated energy, Equation 1, from ballistic tests of individual MAS components. In this table, it is important noticing the much greater decrease in the

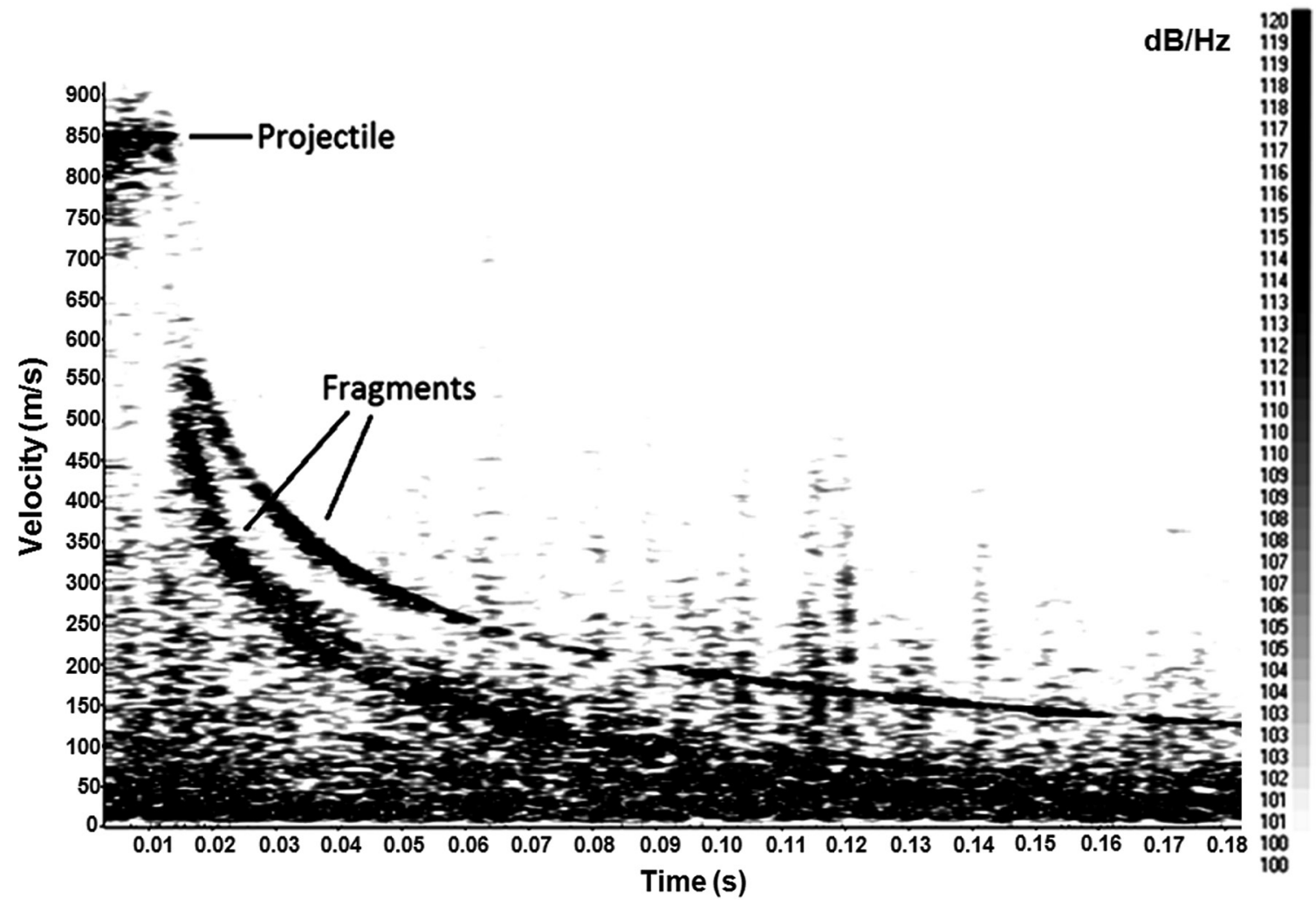

Figure 7. Radar spectrum for the ballistic test of an $\mathrm{Al}_{2} \mathrm{O}_{3}$ ceramic target. 


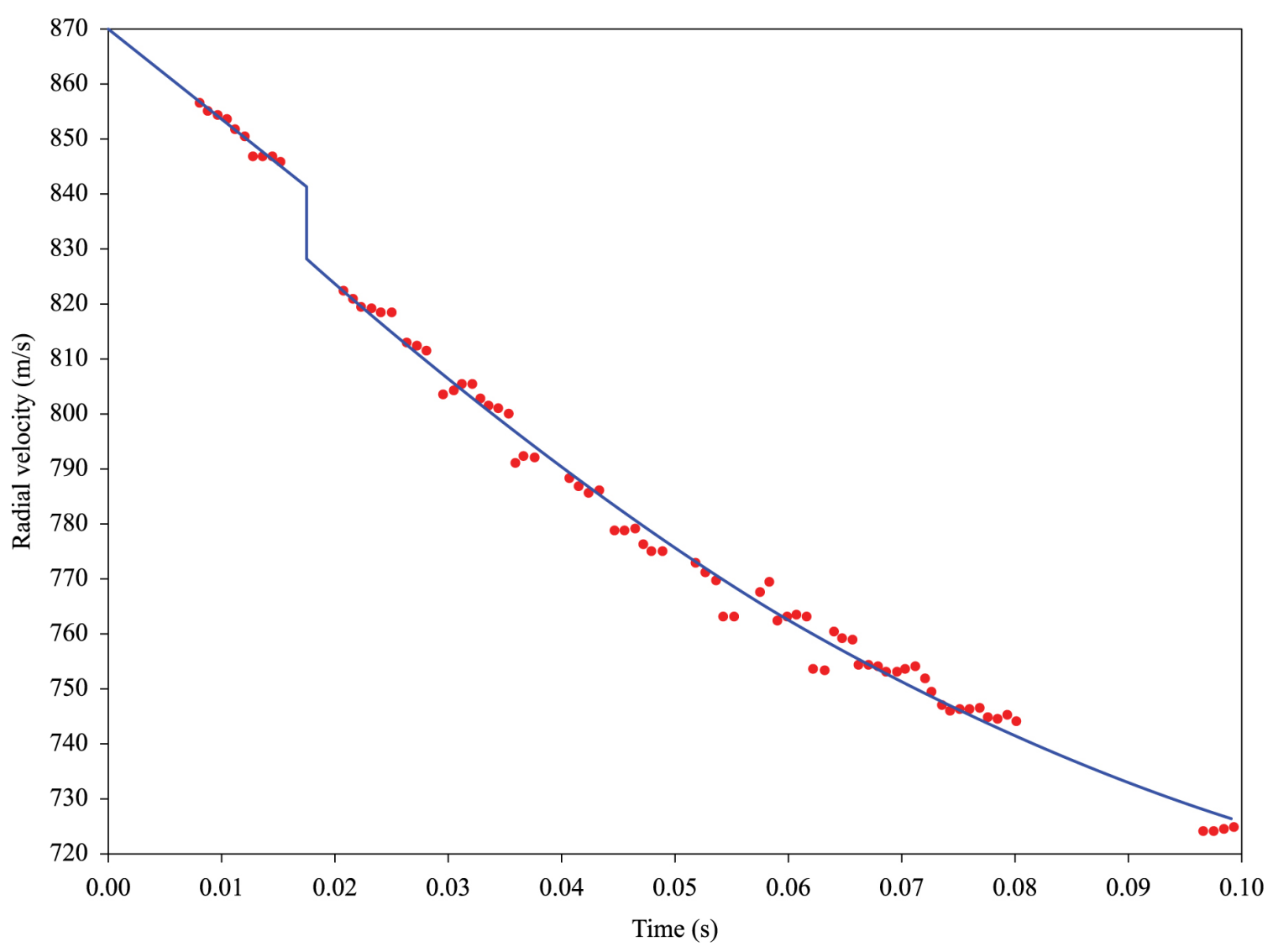

Figure 8. Velocity attenuation experimental points and adjusted curve for the ballistic test of a sisal composite.

Table 2. Impact and residual velocities together with internally dissipated energy in individually ballistic tested MAS components.

\begin{tabular}{cccc}
\hline $\begin{array}{c}\text { MAS } \\
\text { Component }\end{array}$ & $\begin{array}{c}\mathbf{v}_{\mathbf{i}} \\
(\mathbf{m} / \mathbf{s})\end{array}$ & $\begin{array}{c}\mathbf{v}_{\mathbf{r}} \\
(\mathbf{m} / \mathbf{s})\end{array}$ & $\begin{array}{c}\Delta \mathbf{E}_{\mathbf{d}} \\
(\mathbf{J})\end{array}$ \\
\hline $\begin{array}{c}\mathrm{Al}_{2} \mathrm{O}_{3} \\
\text { Ceramic }\end{array}$ & $848 \pm 6$ & $567 \pm 43$ & $1,920 \pm 223$ \\
$\begin{array}{c}\text { Aramid } \\
\text { Fabric }\end{array}$ & $848 \pm 6$ & $841 \pm 7$ & $58 \pm 29$ \\
$\begin{array}{c}\text { Sisal } \\
\text { Composite }\end{array}$ & $848 \pm 6$ & $835 \pm 6$ & $106 \pm 11$ \\
Plain Epoxy & $850 \pm 2$ & $827 \pm 6$ & $190 \pm 62$ \\
\hline
\end{tabular}

ceramic impact velocity $\left(\mathrm{v}_{\mathrm{i}}\right)$ to the residual velocity $\left(\mathrm{v}_{\mathrm{r}}\right)$, about $33 \%$, as compared to less than $3 \%$ for the other components. Consequently, the internally dissipated energy in the ceramic, $1,920 \mathrm{~J}$ is comparatively much higher. As a relevant result, the aramid fabric dissipates the lowest energy, $58 \mathrm{~J}$. This is coherent with the result in Table 1, where the aramid fabric presents the worst ballistic performance associated with the deepest indentation.

The possible explanation for the relatively low individual absorption energy of the aramid fabric in the present ballistic tests might be related to the type of ammunition. A high energy sharp-pointed $7.62 \times 51 \mathrm{~mm}$ bullet probably penetrates easily in between the aramid fabric weave by simply separating or pulling out the yarns. This is certainly not the case of energy-reduced blunt fragments resulting from eroded and broken projectile after striking the front ceramic layer in a MAS. In other words, individually, an aramid fabric is not as effective barrier to a 7.62 bullet as compared to a sisal composite or even a plain epoxy, in which the brittle matrix is able to dissipate more energy, Table 2, by fragmentation. However, by backing a front ceramic, which not only reduces the velocity (33\%) and dissipates most of the impact energy but also blunts the fragmented projectile, an aramid fabric might become a more effective MAS component.

Once again, the reader should be reminded that a sisal composite, in addition to $20 \%$ superior ballistic performance in confront with aramid fabric, Table 1, attends the $\mathrm{NIJ}^{2}$ standard limits for body trauma and sensibly reduces the MAS weight and price.

\section{Conclusions}

- A multilayered armor, in which the conventional aramid fabric plies, following after a front $\mathrm{Al}_{2} \mathrm{O}_{3}$ ceramic, was replaced by a same thickness epoxy matrix composite reinforced with sisal fiber attended the NIJ trauma limit after ballistic tests with $7.62 \times 51 \mathrm{~mm}$ ammunition.

- The ballistic performance of the sisal composite was found to be $20 \%$ more ballistic effective (smaller indentation in clay witness) than the aramid with the 
additional advantage of being 5\% lighter and $31 \%$ cheaper.

- In addition to fiber rupture that occur in the aramid fabric, the sisal composite also contributes to dissipate the fragments (projectile or ceramic) energy by crack nucleation and propagation in the epoxy matrix.

- Ballistic tests of each individual (separated) components revealed that the $\mathrm{Al}_{2} \mathrm{O}_{3}$ ceramic tile dissipates around $55 \%$ of the 7.62 bullet impact energy, while the other components dissipate less than $3 \%$. Coherent with its ballistic performance, the aramid fabric presented,

\section{References}

1. Jacobs MJN and Van Dingenen JLJ. Ballistic protection mechanisms in personal armor. Journal of Materials Science. 2001; 36(13):3137-3142. http://dx.doi.org/10.1023/A:1017922000090.

2. National Institute of Justice - NIJ. NIJ Standard 0101.06: ballistic resistance of personal Body Armor. Washington: US Department of Justice; 2008.

3. Bazhenov S. Ballistic protection mechanisms in personal armors. Journal of Materials Science. 1997; 32(15):4167-4173. http:// dx.doi.org/10.1023/A:1018674528993.

4. Abrate S. Ballistic impact on composite structures. 1st ed. Cambridge: Cambridge University Press; 1998. p. 215-220.

5. Medvedovski E. Lightweight ceramic composite armor system. Advances in Applied Ceramics. 2006; 105(5):241-245. http:// dx.doi.org/10.1179/174367606X113537.

6. Tasdemirci A, Tunusoglu G and Guden M. The effect of the interlayer on the ballistic performance of ceramic/composite armors: experimental and numerical study. International Journal of Impact Engineering. 2012; 44:1-9. http://dx.doi. org/10.1016/j.ijimpeng.2011.12.005.

7. Brown AS. New options in personnal ballistic protection. High Performance Composites. 2003; (2):23-26.

8. Lee YS, Wetzel ED and Wagner NJ. The ballistic impact characteristic of $\operatorname{Kevlar}^{\circledR}$ woven fabrics impregnated with a colloidal shear thickening fluid. Journal of Materials Science. 2003; 38(13):2825-2833. http://dx.doi.org/10.1023/A:1024424200221.

9. Anderson CE Jr and Morris BL. The ballistic performance of confined $\mathrm{Al}_{2} \mathrm{O}_{3}$ ceramic tiles. International Journal of Impact Engineering. 1992; 12(2):167-187. http://dx.doi.org/10.1016/0734743X(92)90395-A.

10. Shokrieh MM and Javadpour GH. Penetration analysis of a projectile in ceramic composite armor. Composite Structures. 2008; 82(2):269-276. http://dx.doi.org/10.1016/j. compstruct.2007.01.023.

11. Medvedovski E. Ballistic performance of armor ceramics: influence of design and structure - part I. Ceramics International. 2010: 36(7): 2103-2115.

12. Medvedovski E. Ballistic performance of armor ceramics: influence of design and structure - part II. Ceramics International. 2010; 36(7): 2117-2127.

13. Louro LHL and Meyers MA. Effect of stress state and microstructural parameters on impact damage of alumina-based ceramics. Journal of Materials Science. 1989; 24(7):2516-2532. http://dx.doi.org/10.1007/BF01174523.

14. Abrate S. Wave propagation in lightweight composite armor. Journal de Physique. IV. 2003; 110:657-662. http://dx.doi. org/10.1051/jp4:20020768. individually, the lowest energy dissipation. This might be attributed to the easy penetration of the sharp-pointed bullet in between the yarns of the fabric weave of the aramid or the sisal fibers.

\section{Acknowledgements}

The authors thank the support to this investigation by the Brazilian agencies: CNPq, CAPES and FAPERJ. It is also acknowledged the permission to the use of the SEM microscope by the PEMM from COPPE/UFRJ.

15. Lee BL, Song JW and Ward JE. Failure of spectra polyethylene fibre-reinforced composites under ballistic impact loading. Journal of Composite Materials. 1994; 28(13):1202-1226. http://dx.doi.org/10.1177/002199839402801302.

16. Hine PJ, Duckett RA, Morye SS, Carr DJ and Ward IM. Modelling of the energy absorption. Composites Science and Technology. 2000; 60:2631-2642.

17. Morye SS, Hine PJ, Duckett RA, Carr DJ and Ward IM. Modeling of the energy absorption by polymer composites upon ballistic impact. Composites Science and Technology. 2000; 60(14):2631-2642. http://dx.doi.org/10.1016/S02663538(00)00139-1.

18. Meyers MA. Dynamic behavior of materials. New York: John Wiley \& Sons; 1994. p. 183-201.

19. Monteiro SN, Lopes FPD, Barbosa AP, Bavitori AB, Silva ILA and Costa LL. Natural lignocellulosic fibers as engineering materials: an overview. Metallurgical and Materials Transactions. A, Physical Metallurgy and Materials Science. 2011; 42(10):29632974. http://dx.doi.org/10.1007/s11661-011-0789-6.

20. John MJ and Thomas S. Biofibers and biocomposites. Carbohydrate Polymers. 2008; 71(3):343-364. http://dx.doi. org/10.1016/j.carbpol.2007.05.040.

21. Satyanarayana KG, Arizaga GGC and Wypych F. Biodegradable composites based on lignocellulosic fibers: an overview. Progress in Polymer Science. 2009; 34(9):982-1021. http:// dx.doi.org/10.1016/j.progpolymsci.2008.12.002.

22. Monteiro SN, Lopes FPD, Ferreira AS and Nascimento DCO. Natural fiber polymer matrix composites: cheaper, tougher and environmentally friendly. JOM. 2009; 61(1):17-22. http:// dx.doi.org/10.1007/s11837-009-0004-z.

23. Faruk O, Bledzki AK, Fink HP and Sain M. Biocomposites reinforced with natural fibers. Progress in Polymer Science. 2012; 37(11):1555-1596. http://dx.doi.org/10.1016/j. progpolymsci.2012.04.003.

24. Holbery $\mathrm{J}$ and Houston D. Natural fiber reinforced polymer composites in automotive applications. JOM. 2006; 58(11):8086. http://dx.doi.org/10.1007/s11837-006-0234-2.

25. Zah R, Hischier R, Leão AL and Brown I. Curaua fibers in automobile industry: a sustainable assessment. Journal of Cleaner Production. 2007; 15(11-12):1032-1040. http://dx.doi. org/10.1016/j.jclepro.2006.05.036.

26. Njuguna J, Wambua P, Pielichowski K and Kayvantash K. Natural-fibre-reinforced polymer composites and nanocomposites for automotive applications. In: Kalia S, Kaith BS and Kaurs I, editors. Cellulose fibers: bio-and nano-polymer composites. Berlin: Springer-Verlag; 2011. p. 661-700.

27. Monteiro SN, Margem FM, Pereira AC, Simonassi NT and Oliveira MP. Charpy impact tests in epoxy matrix composites 
reinforced with continuous sisal fibers. Materials Science Forum. 2014; 775-776:290-295. http://dx.doi.org/10.4028/ www.scientific.net/MSF.775-776.290.

28. Wambua P, Vangrimde B, Lomov S and Verpoest I. The response of natural fibre composites to ballistic impact by fragment simulating projectiles. Composite Structures. 2007; 77(2):232240. http://dx.doi.org/10.1016/j.compstruct.2005.07.006.
29. Monteiro SN, Margem FM, Inacio WP, Pereira AC and Oliveira MP. Tensile properties of epoxy composites reinforced with continuous sisal fibers. Materials Science Forum. 2014; 775776:284-289. http://dx.doi.org/10.4028/www.scientific.net/ MSF.775-776.284. 